\title{
Beyond Business-IT Alignment - Digital Business Strategies as a Paradigmatic Shift: A Review and Research Agenda
}

\author{
Cathrin Kahre \\ University of Duisburg-Essen \\ Cathrin.Kahre@stud.uni-due.de
}

\author{
David Hoffmann \\ University of Duisburg-Essen \\ David.Hoffmann@uni-due.de
}

\author{
Frederik Ahlemann \\ University of Duisburg-Essen \\ Frederik.Ahlemann@uni-due.de
}

\begin{abstract}
Since the 1990s, business-IT alignment has been considered the appropriate organizational frame for business and IT strategies. Thereafter, with the rising importance of innovative digital technologies for performance and competitiveness, the concept of digital business strategies (DBS) emerged. The fusion of business and IT strategies is presumed to account for the inevitable transformations that digital technologies triggered. This paradigmatic shift poses new challenges to practitioners and researchers, as current assumptions regarding strategizing processes need to be questioned. This study sets out to provide a structured clarification of the current digital business strategies knowledge base. It provides a threefold contribution by: 1) structuring the research efforts on digital business strategies, 2) uncovering knowledge gaps and 3) developing an agenda for future research.
\end{abstract}

\section{Introduction}

Digital technologies increasingly determine our everyday life, especially the business world [12]. In this regard, researchers agree that IT can provide sustainable competitive advantages that significantly influence corporate success [58].

While the importance of innovative technologies steadily increased, IT/IS strategies were mostly treated as subordinate to business strategies: Practitioners as well as researchers called for business-IT alignment, which emphasizes the business value of IT but also its role of supporting business strategy $[11,13]$. While $78 \%$ of US CEOs are concerned about the rapid pace of technological change [61], 48\% of CIOs still spend most of their time aligning IT operations with overall corporate objectives [32]. More recently, the concept of digital business strategies (DBS) came to the fore, postulating a merger of business and IT strategies as a prerequisite for driving innovations and remaining competitive $[8,50]$. This phenomenon constitutes a global paradigmatic shift in understanding strategic management in the age of digital economics [70], accounting for the transformation of products, services, processes, organizational structures as well as business models through innovative technologies [52,65,75]. Since business and IT strategies should no longer solely "complement" [11:300] each other, it is imperative to assess how the fusion of business and IT affects organizations and their strategizing processes.

While literature on business-IT alignment is extensive and mature, the discussion on DBS is rather disconnected, with a lack of transparency and focus. The unique notion of DBS differs fundamentally from the traditional understanding of business and IT strategies or the concept of business-IT alignment, so that current assumptions regarding the strategizing process must be questioned. Although scholars constantly add remarkable insights to the body of knowledge on constituents of DBS, neither the effects of firm and environmental factors on DBS nor the relation and causal effect between the factors preceding and influencing the strategizing process have been assessed holistically.

To fertilize future research endeavors, a comprehensive overview integrating prior research on dominant themes of DBS and their relationships is in demand. To reach this aim, we compiled the following questions to guide our research: "Which environmental and organizational conditions and changes influence the content of digital business strategies, and what are the associated outcomes?" and "Which issues and phenomena at the intersection of strategy, technology, and organization have to be revisited in the light of digital business strategies?" We assess the existing body of knowledge to identify gaps in the understanding of DBS, and propose paths for future research. The contribution of this study is threefold: It provides a $\mathrm{s}$ of contributions in the area of DBS, identifies gaps in research, and shows avenues for addressing these gaps by providing a research agenda. 
The remainder of this paper is structured as follows: The subsequent section explains the necessary foundations and derives a research framework for our analysis. Next, the employed research method is described. Chapter 4 presents a synthesis of the current knowledge base. This is followed by the outline of identified research gaps and an agenda for future research on DBS. The conclusion provides a summary, including contributions and limitations.

\section{Background and research framework}

The primary goal of IT investments is traditionally seen as supporting organizations to achieve business objectives. Consequently, firms strive for consensus among business and IT functions [11]; an idea that is further established in the beginning of the 1990s through the concept of business-IT alignment [28]. Research has shown that the successful alignment of business and IT/IS strategy leads to better firm performance [11]. As a prominent example, the Strategic Alignment Model (SAM) by Henderson and Venkatraman [28] was widely recognized as the base for business-IT alignment research, with several extensions and modifications over the past two decades (e.g. [4,41]). However, in most of the research on business-IT alignment, authors emphasized the subordinate role of IT strategies in supporting, not mutually shaping, business strategy $[11,13]$.

The recent trend of digitalization leads to changes in this understanding of IT: An increasing digitalization of products and services significantly transforms existing business models, corporate structures, and whole industries $[8,12]$. The realization of new opportunities is enabled, dramatically reshaping the whole business [22]. This development calls for the active transformation of processes and systems through redefinition of the organization's mission, structure and strategy in order to stay competitive [53]. As technologies are integrated into business services and products, they exceed the usual function of supportively complementing the business [50,55].

These aspects significantly influence the formulation of business strategies, leading to more recent research on the topic of digital business strategies [8]. DBS is a rather new concept, introduced by Mithas and Lucas in 2010 [50] and elaborated by Bharadwaj et al. three years later [8]. It represents an organizational strategy that is "formulated and executed by leveraging digital resources to create differential value" [8:472], triggered by the emergence of innovative and disruptive technologies [49]. Bharadwaj et al. [8] concretize the term by defining four themes of interest, namely scope, scale, speed, and source. Scope, which defines the portfolio of products and services, highlights that DBS not only unite corporate and IT/IS strategies but integrates the whole business ecosystem. In this sense, scale, i.e. leveraging network effects, becomes increasingly important due to the more connectivity between partners and competitors. Besides connectivity, digitalization also leads to a higher speed of business activities. Lastly, the sources of value creation are expanded as digital technologies allow for new business models, extending traditional chains of supply and delivery [8].

In sum, DBS reflect a "new logic of competitive strategy" [75:538], where boundaries between business and IT strategy become blurred [57]. Dynamically synchronized, business and IT are mutual drivers of strategic change, business value and ultimately competitive advantage $[8,52,65]$.

As DBS become more important for researchers as well as practitioners, understanding their core becomes imperative. In this regard, it is of interest to examine the changes in the content of a strategy as well as the dominant relationships among important elements [30]. Business strategists differentiate between common components, which are characteristic of a specific strategy. Basic building blocks are organizational conditions fostering the demand for a new or altered strategy, e.g. dynamic capabilities, [30,31,33,62] and exogenous factors moderating the strategy formulation and adaptation process like environmental turbulence $[30,31,33,62]$. Likewise considering the outcomes of strategy implementation is essential, with performance outcomes being most prominent in management literature $[30,31,62]$. In terms of the relation among the elements, organizations face increasingly turbulent conditions today, and therefore try to align themselves with shifting competitive and technological environments through measures of strategic change to survive and stay effective [36]. In particular, this includes organizational changes and changes in the content of a firm's core strategy. Reciprocally, strategic change also includes how a firm aims to change its environment through adjusting strategy.

To assess these different aspects within the paper, we adopt an analytical framework based on the work of Rajagopalan and Spreitzer [63], who investigated strategic changes from a rational, learning and cognitive perspective. While Rajagopalan and Spreitzer consider managerial actions as central in the strategic change process, their argumentation reveals a lack of distinction between "Managerial actions" and "Changes in the content of strategy" [63]. We therefore neglect this element and derive our analytical framework as visualized in Figure 1.

Consistent with the abovementioned components and the learning perspective, "Organizational 
conditions \& changes" reflect both, internal weaknesses inhibiting changes and strengths supporting the need for change. "Environmental conditions \& changes" describe the exogenous influencing factors characterized by uncertainty and dynamism. "Organizational outcomes" focus on the effects of strategic change. The reciprocal relationships between the respective elements are incorporated into the framework.

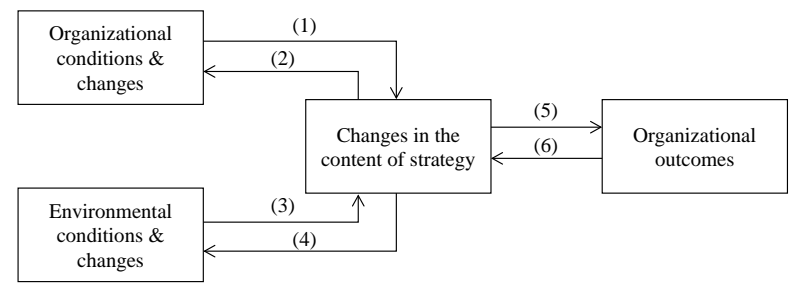

Figure 1: Analytical framework adapted from Rajagopalan and Spreitzer [63]

\section{Research method}

This study utilizes a structured literature review approach to assess the current knowledge base and derive possible research opportunities with regard to DBS. We employed established recommendations $[14,71]$ to guide our review in order to unveil the current research that may help to describe, understand, and explain the phenomenon.

For the literature selection, leading databases (EBSCOhost, JSTOR, Science Direct) were searched for combinations of "IT strategy", "IS strategy", "digital strategy", "digital business strategy", or "strategy" with "digitalization” or "digitization”. To allow for a literature sample that is as comprehensive as possible, the search was not limited to certain sources or a specific timeframe, as such restrictions would have unnecessarily diminished the list of suitable publications. This process was complemented with a forward and backward search approach to yield additional publications. In doing so, 59 potentially interesting publications were identified. After reading the titles and abstracts, publications that did not fit the scope of our research were excluded from the sample. We then studied the full text and excluded publications not related to our topic. As a result of this refinement, we considered 39 publications.

To support the literature classification and analysis, a classification scheme adopted from Urbach et al. [69] was developed. The adjusted framework guides the categorization mainly with regard to the content, native discipline, and research approach. To extract the main messages the authors conveyed, we applied the coding technique for literature analysis Wolfswinkel et al. [74] proposed and followed an inductive-deductive approach to literature classification [46]. In the first phase of open coding, relevant passages were highlighted and paraphrased. With the help of axial coding, those aspects were reclassified across all stuides to common categories.

The output of this inductive classification derived from literature was combined with our prior research on the essential elements and relations of strategizing processes as indicated at the end of the background chapter, by deductively mapping the objects of analysis to our conceptual framework adapted from Rajagopalan and Spreitzer [63].

\section{Results}

The literature review illustrates the rising importance of DBS for theory as well as practice: As more than $80 \%$ of the studies identified were published between 2010 and 2016, the results emphasize the novelty of the phenomenon and its gains in receiving attention in the scientific community.

The categorization based on the classification scheme adopted from Urbach et al. [69] is visualized as a part of the concept matrix in table 1 . The framework applied to identify the focus areas of the publications reveals a diverse discourse on DBS. The following sections present a content-wise and in-depth description of the findings, structured according to our analytical framework. Insights about interrelationships are incorporated in the respective sections.

\subsection{Organizational conditions and changes}

A prominent organizational precondition for the formulation of DBS is a change in the understanding of IT. As mentioned in section 2, recent research suggests that business-IT alignment no longer represents the suitable strategic posture. Companies should not regard IT/IS strategies as subordinate or sumpplementary to corporate strategy anymore, but as coequal [8]; an understanding of IT which is reflected in the term fusion view [21,57]. If the merger of IT/IS and business strategies permeates the strategists' mindsets, DBS rise $[8,13]$.

Appropriate organizational structuring is another precondition for the formulation of DBS. Literature indicates that governance as well as power structures should account for the fusion of business and IT [51]. In this sense, leadership and accountability are considered fundamental success factors for effective DBS [47]. Organizations must decide on the senior manager in charge of the digitalization and development of DBS as well as associated report lines [3] and suitable incentive structures aligned with the 
digital strategy's objectives [45]. When it comes to the definition of new business models by means of innovative technologies, organizations have to ensure that the IT is aware to senior management's tactical and strategic plans early on [38]. Equally, the design and implementation of "digital governance" structures requires the joint work of IT and business representatives to ensure synchronized efforts and prioritizing initiatives [29,38].

As innovation is seen as the result of recombining existing resources [39,43], researchers strengthen the importance of dynamic capabilities to quickly adapt to changing conditions and reconfigure the existing resource base $[21,49]$. While the concept of dynamic capabilities, describing a firm's ability to “integrate, build, and reconfigure internal and external competencies to address rapidly changing environment” [68:516], by itself is not new [20], it gains increasing attention in the context of digital innovations. The concept is now differentiated into "traditional" planned and improvisational dynamic capabilities, enabling spontaneous but not necessarily uncoordinated change in turbulent environments [21]. The resulting flexibility allows firms to respond to opportunities in the environment more easily and avoid potential threats from unexpected developments in the market [19].

However, structural inertia might pose a threat to a quick adoption to changes in the digital ecosystem, which highlights the stability of organizational arrangements opposed to environmental change [27]. In this sense, current research also employs the path dependence theory, which provides explanations for the reduction of managerial scope of action through self-reinforcing strategic patterns on organizational and technical levels over time. Path-dependent organizations, seen as socio-technical systems, face challenges when it comes to the timely adoption of innovation due to coordination problems and high switching cost [67].

\subsection{Environmental conditions and changes}

According to our literature review, several exogenous factors influence the formation and implementation of DBS. The increased availability and ubiquity of IT diminishes the significance of technologies themselves but enforces their effective and advantageous utilization [21,65]. Technologies progressively turn into "hygiene factors" [35,65]: As their impact declines, an effective application to innovative business models becomes the distinctive feature $[35,56]$. Viewed as a service ecosystem with a set of mostly loosely coupled actors engaged in the creation and delivery of value, the environment requires organizations to prepare themselves to be flexible and maintain a shared worldview among participating actors $[39,44]$. While some organizations can achieve leading positions and power in these ecosystems, Markus and Loebbecke [44] challenge common beliefs in the competitive advantage of single, powerful actors. They suggest the consideration of business communities, which consist of multiple, partially overlapping ecosystems with several dominant actors aiming for supremacy.

According to El Sawy et al. [21], information systems reinforce environmental turbulence and necessitate their strategic use [56]. Organizations must be able to respond quickly to dynamism and turbulence, characterized by demand uncertainty, technological discontinuity and unpredictable changes in an industry [21,52]. The effective use of IT is therefore imperative for organizations "to be alert, predict the future, and effectively compete" [25:638].

At the same time, digital strategic changes influence the environment: Markets are confronted with altered strategic directions and ecosystems, which necessitate new forms of digital partnerships [9]. These can be linked to the aforementioned firm capacities like market adoption and dynamic capabilities, as well as the capability to design and manage networks of interacting organizations [8].

Research points out that path-dependent organizations are either unwilling or unable to exploit opportunities arising from emerging information systems [64]. In this sense, Wenzel et al. [72,73] highlight that innovative technologies have the potential to severely disrupt strategic paths of organizations. They represent an environmental destabilizer for the self-reinforcing mechanism of strategic paths and therefore require a repositioned or adapted business strategy [73]. Without such adjustments, the disruption will induce the demise of the organizational path. Authors in the field of path dependency therewith support the demand for DBS, by shedding further light on the disruptive nature of information systems on organizations.

\subsection{Changes in the content of strategy}

According to Bharadwaj et al. [8], "how, when, and why" innovative technologies impact the portfolio of products and services as well as the definition of necessary activities to create and deliver the portfolio [8] should be of particular interest. As digital products and services become "fundamental driver[s] of business value creation” [8:480], organizations should imagine digital strategy frameworks that introduce new sources of value creation [76]. Digital innovations might disrupt traditional value chains, often leading to 
new product and service portfolios, and addressing different markets and customer segments [45]. Consequently, digitalization induces networks of competitors, partners and customers that need to be incorporated into DBS $[8,44]$. This is specified through the idea of value co-creation, "which views value or experience as cocreated by the service offer(er) and the service beneficiary” [39:157]. The diverse opportunities offered by innovative IT induces ecosystems of interdependent, co-creating entities [40], which calls for appropriate internal processes and distribution of roles to enhance the value the customer experiences [39]. Digitalization therefore demands synchronizing IT technologies and resources with

Table 1: Concept matrix

\begin{tabular}{|c|c|c|c|c|c|c|c|c|c|c|c|c|c|c|c|c|c|c|c|c|c|c|c|c|}
\hline \multirow[b]{2}{*}{ Literature } & \multicolumn{9}{|c|}{ Focus } & \multicolumn{4}{|c|}{ Discipl. } & \multicolumn{2}{|c|}{ Unit } & \multicolumn{3}{|c|}{ Type } & \multicolumn{6}{|c|}{ Approach } \\
\hline & 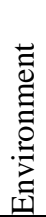 & 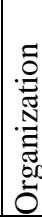 & & 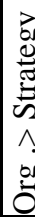 & 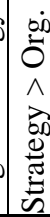 & 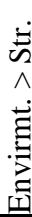 & & 定 & & & & & & 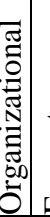 & 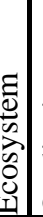 & 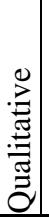 & 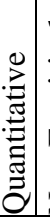 & 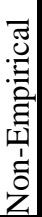 & & 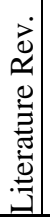 & & 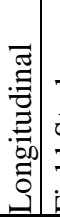 & 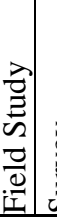 & \\
\hline [3] Banker et al. (2011) & & • & - & . & - & & & & & . & 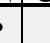 & & ( & - & & & $\cdot$ & & 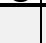 & & & $\cdot$ & & \\
\hline [6] Bennis (2013) & - & & & & - & • & & & & • & - & & (2. & - & & & & $\cdot$ & - & & & & & \\
\hline [7] Berman (2012) & - & & & & & & & & & & - & & 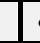 & - & & & & - & - & & & & & \\
\hline [8] Bharadwaj et al. (2013) & • & • & - & & • & $\cdot$ & & - & & . & 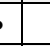 & & & • & & & & $\cdot$ & - & & & & & \\
\hline [9] Bharadwaj et al. (2013) & & & & & - & & & & & . & . & & & - & & & & - & • & & & & & \\
\hline [11] Chan and Reich (2007) & & • & & & & & & & & . & . & & & - & & & & $\cdot$ & & $\cdot$ & & & & \\
\hline [12] Collin (2015) & & & & & - & & & & & - & 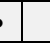 & & & - & & & & $\cdot$ & $\cdot$ & & & & & \\
\hline [13] Coltman et al (2015) & - & - & & & & - & & & & - & b & & & • & & & & - & - & & & & & \\
\hline [15] Dehning et al. (2003) & - & & - & & - & & • & & & - & ? & & & • & & & - & & ( & & & - & & \\
\hline [16] Dehning and Stratopoulos (2003) & - & • & • & & & • & $\cdot$ & & & . & 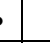 & & & - & & & • & & 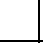 & & & - & & \\
\hline [17] Dhar and Sundararajan (2007) & - & • & & & • & & & & & - & - & & & & - & & & - & - & & & & & \\
\hline [19] Drnevich and Croson (2013) & - & • & • & • & & • & & & & . & 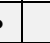 & & & - & & & & $\cdot$ & - & & & & & \\
\hline [21] El Sawy et al. (2010) & - & $\cdot$ & • & & - & • & & & & . & 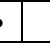 & & & & - & & & - & - & & & & & \\
\hline [24] Ganguly (2015) & & • & • & & - & & & & & & • & & & - & & $\cdot$ & & & & & - & & & \\
\hline [25] Granados and Gupta (2013) & - & • & & & & - & & & & ( & . & & & - & & & & - & - & & & & & \\
\hline [29] Hiekkanen (2015) & - & - & • & & & & & & & 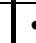 & 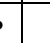 & & & - & & & & - & - & & & & & \\
\hline [34] Keen and Williams (2013) & - & & $\cdot$ & & - & & & & & ( & . & & & - & & & & $\cdot$ & - & & & & & \\
\hline [35] Korhonen (2015) & - & & & & & & & & & 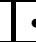 & 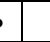 & & & - & & & & $\cdot$ & - & & & & & \\
\hline [37] Lucas et al. (2013) & • & & & & & • & & & & 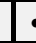 & 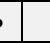 & & & - & & & & $\cdot$ & - & & & & & \\
\hline [38] Luftman and Brier (1999) & & • & & - & - & & & & & & & ( & & - & & $\cdot$ & & & 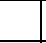 & & & - & & \\
\hline [39] Lusch and Nambisan (2015) & - & • & & - & - & - & • & & & . & & & & & - & & & - & - & & & & & \\
\hline [43] Mao et al. (2012) & & • & & - & - & & & & & ( & & & & - & & & & $\cdot$ & & • & & & & \\
\hline [44] Markus and Loebbecke (2013) & - & & & & & - & - & & & c & & & & & - & & & - & - & & & & & \\
\hline [45] Matt et al. (2015) & & • & • & & - & & & & ( & ( & & & & - & & - & & $\cdot$ & - & & & & & \\
\hline [47] McKeown and Philip (2003) & & $\cdot$ & $\cdot$ & - & - & & & . & & 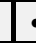 & & & & - & & $\cdot$ & & . & 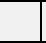 & & • & & & \\
\hline [48] Merali et al. (2012) & • & • & & • & & • & $\cdot$ & & & ? & & & & - & & & & $\cdot$ & & • & & & & \\
\hline [49] Mithas et al. (2012) & - & • & & & - & • & . & & & ( & & & & - & & & & $\cdot$ & - & & & & & \\
\hline [50] Mithas and Lucas (2010) & - & - & • & - & - & & - & . & & ( & & & & - & & & & $\cdot$ & - & & & & & \\
\hline [51] Mithas et al. (2011) & & & • & & & & & . & & s & & & & - & & & - & & & & & - & & \\
\hline [52] Mithas et al. (2013) & - & & & & & - & & & & se & & & & - & & & • & & 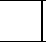 & & & - & & \\
\hline [55] Pagani (2013) & • & $\cdot$ & & & - & • & - & & & 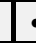 & & & & & $\cdot$ & - & & & - & & & & - & \\
\hline [56] Pavlou and El Sawy (2006) & • & & $\cdot$ & - & & • & & . & & s & & & & - & & & $\cdot$ & & 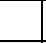 & & & & $\cdot$ & \\
\hline [57] Peppard et al. (2014) & & • & & - & & & & & & . & & & s. & - & & 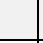 & & - & - & & & & & \\
\hline [65] Sandberg (2014) & • & • & • & - & - & • & & . & & 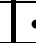 & & & (e & - & & $\cdot$ & & & & & - & & & \\
\hline [66] Setia et al. (2013) & & • & $\bullet$ & - & - & & & . & & s & & & & • & & & $\cdot$ & & & & & & & - \\
\hline [72] Wenzel et al. (2015) & & • & & $\bullet$ & & & & & & . & & & & - & & - & & & & & & - & & \\
\hline [73] Wenzel et al. (2015) & • & • & & $\cdot$ & & • & & & & 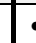 & & & & - & & - & & & & & - & & & \\
\hline [75] Woodard et al. (2013) & - & - & & & • & - & $\bullet$ & & & & & & & - & & $\bullet$ & & & & & - & & & \\
\hline [76] Yoo et al. (2010) & - & - & & & - & • & - & & & & & & & - & & & & $\bullet$ & $\bullet$ & & & & & \\
\hline $\mathrm{N}=39$ & 26 & 27 & 6 & 14 & 22 & 19 & & 1 & & & 65 & & & 34 & 5 & 9 & 7 & 23 & 20 & 3 & 5 & 8 & 2 & 1 \\
\hline Share in \% & 67 & 69 & & 36 & 56 & 49 & & & & & 25 & & & & & 23 & 18 & 59 & 51 & 8 & & 21 & & 3 \\
\hline
\end{tabular}


digital value propositions, becoming a part of key resources and processes [43]. Another activity is the careful choice and adaptation of disruptive technologies as well as the effective leveraging of IT capabilities $[37,56]$.

In terms of the impact of DBS on organizations and their structure, businesses are confronted with new challenges since altered strategies, internal processes, capabilities as well as intra-organizational relationships are required [8]. In this context, the importance of organizational learning next to strategic design actions cannot be overemphasized [48]. By establishing a corporate knowledgebase, the development of further capabilities and therewith the opportunity for more flexibility and adaptability is enabled [43,47]. Furthermore, the activities of organizational leaders change dramatically because they need to decide about the implementation of innovative technologies [6]. According to Bharadwaj et al., this represents one of the major challenges with regard to DBS, as leaders need new, especially adaptive, capabilities to manage the process $[6,9]$.

\subsection{Organizational outcomes}

An expanded or reconfigured digital business scope helps organizations to cultivate opportunities which let them expand into new markets and gain a competitive advantage [8,19]. However, research on the performance outcomes of DBS is scarce. In terms of nonfinancial improvements, faster and better adoption to changing environmental conditions and customer needs can be achieved [7,23,57], enabling a higher differentiation from competitors and extended sustainability [8,24,52]. While constantly changing environmental conditions erode strategic advantages, organizations leveraging DBS can enhance their flexibility and respond to new opportunities and threats more easily through infrastructural changes and innovations in their value propositions $[19,21]$.

Concerning financial outcomes, researchers empirically traced significant business growth and enhanced profitability back to a successful IT-enabled transformation process [47]. They agree that information technologies and systems, which are effectively leveraged with the help of DBS, offer an enhanced competitive positioning [16], higher performance, productivity and profitability as well as new value propositions [24,34,43,50]. DBS enable greater organizational efficiency and effectiveness [29] through streamlined operations, enhanced resources as well as new capabilities or lines of business [19,23]. These aspects are also related to better financial performance reflected in profitability measures [19,50] like return on sales, return on investment as well as return on assets [24,45].

Few authors analyze, how learning occurs when strategy content changes are realized, by assessing outcomes through defined procedures. Matt et al. [45] highlight the need for a continuous reassessment of the underlying assumptions and the overall transformational progress based on organizational outcomes, however, without providing concrete recommendations about implementation. Conceptually related to the aforementioned path-dependence of organizations, Woodard et al. [75] provide an empirical approach to assess "design moves" which enlarge, reduce, or modify the number of digital artifacts by evaluating the range of available options and technical debt resulting from prior business outcomes.

\section{Discussion and research agenda}

One goal of this study was to assess the current state of knowledge on DBS. As pointed out, the results indicate a significant growth of and increased attention to the environmental and organizational conditions, as well as changes in the strategy of organizations since 2010. The underlying phenomenon of a fusion view of both domains progressively emerged during the late 2000s, when publications on business-IT alignment started to emphasize the use of IT to achieve an overall competitive advantage $[11,56]$.

Recent publications aim beyond the traditional understanding of business-IT alignment: As organizations increasingly digitize their business models and start to recognize the differential value of IT, researchers have postulated the necessity of a "twoway alignment” [13:96] between business and IT [8]. Organizations that possess digital options but are unable to leverage these assets through their processes, will likely fail to capitalize on digital opportunities $[13,21,75]$. Taken together, these insights infer that business processes and capabilities become a means through which IT creates value, creating a new notion of alignment.

We identified several gaps in the DBS field. From a holistic change perspective on digital business strategies, encompassing content, context, and processes [59,63], we came across publications that focus on the inner and outer context as well as the content of DBS. Current research therefore primarily addresses the "why" and "what" of change questions when it comes to DBS. However, research on the "how" of change, which can only be understood from a detailed analysis of the processes focusing on transformational changes, is scarce. In this context, comparative and longitudinal case study research 
might yield reliable empirical findings to explain how organizations formulate and implement DBS.

Only a few authors have adopted dedicated theoretical lenses to ground or reflect their work, with the resource-based view or a capability perspective being the most common underpinning factor $[16,19,48,51,57]$. Substantial IT/business capabilities to leverage digital options and dynamic capabilities to reconfigure the resource base are seen as imperative in sustaining a competitive advantage in the digital era $[13,21]$. While attempts have been made to define "digital capabilities" [65:1] as a collection of routines to leverage digital assets to create differential value, research lacks broader insights on what exactly these digital capabilities are, and how organizations can build the dynamic capabilities to quickly obtain digital capabilities. It might be promising to investigate the emergence of these meta-capabilities, which relate to "learning-to-learn capabilities" [1:34] and enable organizations to change the way they operate, and reconfigure themselves. While scholars from the organizational sciences already produced several publications on capability building and the emergence of dynamic capabilities at the beginning of the millennium (i.e. [77]), there is a lack of knowledge on capability building in the digital era. To account for the influence of technological dynamism and environmental turbulence, future research might employ organizational learning perspectives to explain how, when, and why organizations reconfigure their resource and capability base when confronted with technological disruption and - vice versa - how innovative technologies enable new dynamic capabilities.

Some researchers [8,11,13,38] also employed theories on business-IT alignment, such as SAM and its successors, to reflect on current developments. As stated earlier, the prevalent view on alignment, which has been advocated for two decades, is increasingly challenged and has even been reversed in some cases [13]. As the role of IT transcends beyond enabling the business [39], some questions need to be asked again and answered with renewed intensity. Researchers might explore which organizational processes, structures, and governance mechanisms are suited to achieve "digital alignment" and, using the terminology Henderson and Venkatraman provided [28], which new "alignment perspectives" are offered by digital business strategies.

Besides further steps with regard to already employed theories, we see opportunities to adapt alternative theoretical underpinnings. By using adoption diffusion theories, we would be able to understand the process of when and how digital innovations diffuse in a population, i.e. societies.
Traditional, customer-centric models in this area focus on forecasting long-term growth rates of technologies and sales patterns [5]. While it is interesting how digital products and services diffuse in the market, it could be even more promising to put organizations in the center of this investigation. As our review highlighted technological dynamism, competitive intensity and turbulence as driving forces in digital ecosystems [21,55], developing explanations for the mechanisms how organizational adoption of digital innovations and the incorporation in novel business models take place would be beneficial to assess the value of technologies and innovation capabilities.

Research acknowledges that future organizational activities will not only consist of explorative and innovative endeavors. While organizations should be able to rapidly capitalize on short-term opportunities, operational excellence is still seen as a crucial aspect of being able to deliver new digital business models [48]. While some recognize the paradoxical tension for firms in balancing innovative agility and operative stability [26], others already recommend ambidextrous approaches by establishing organizational duality to explore new innovations and exploit current ideas [2]. Drawing on the notion of ambidexterity, researchers might strive to explain how organizations pursue divergent activities in the light of digital disruption.

Authors emphasize the point that the networked cocreation of value infers a change of organizational structures among factors towards digital ecosystems $[21,55,75]$. As organizations are increasingly dependent on the environment and its resources, Resource Dependence Theory (RDT) [60] might provide a suitable conceptual lens. RDT argues that all organizations depend on other organizations for the provision of critical resources, and that this interorganizational dependence is often reciprocal. RDT was frequently applied to investigate the mechanics of different inter-organizational arrangements, such as alliances, joint ventures, and mergers and acquisitions $[18,54]$. In the context of DBS, researchers postulate that organizations should manage uncertainty to their advantage to achieve a leading position in the ecosystem [49]. While researchers like Pagani [55] already provided insights into how digital ecosystems evolve and what their dynamics of value creation are, RDT might serve as a theoretical lens to explain what actions organizations can take to use environmental uncertainty to their advantage. The digital ecosystem may be envisioned as a "hostility-munificence continuum" [10:551], characterized by the scarcity or abundance of resources and the ability to support sustained growth. Several researchers have also proposed a meta-theoretical view by combining RDT with the resource-based view due to their 
complementary focus on resources [54]. For example, a combined approach may provide novel explanations of how organizations can achieve a competitive advantage by obtaining valuable resources from digital ecosystems.

While the largest share of our review sample consists of non-empirical publications like conceptual studies, editorials, or research commentaries, only a small number employed empirical approaches; especially field study and survey research designs are rare. We encourage researchers to explore the utility of quantitative methods to generalize and test emerging theories in the field. Nevertheless, we are confident that more qualitative research will extend our knowledge on the variables and their relationships that lead to the formation of DBS before applying rigorous quantitative research. As soon as we have accumulated more knowledge of the variables of DBS and how they will be measured, survey and field study research as well as a combination of research methods may yield reliable insights on DBS and their impact on the alignment perspective [42].

It became apparent that the impact of DBS on organizational outcomes and reciprocal feedback mechanisms have up to now not been examined extensively $[9,37,66]$. We believe it is important to extend our knowledge on the impact of strategic changes on performance, because this relationship may be fundamentally different in a digital ecosystem compared to traditional environments [39,55]. To summarize, digital business strategies still offer plenty of room for investigation, quantitative as well as qualitative.

\section{Conclusion}

This study examines the current knowledge base on DBS to identify the influence of this paradigmatic shift on research and practice. In accordance with our first research question, the assessment of publications resulted in a detailed overview of the environmental, organizational conditions, and changes influencing the strategizing process towards DBS. Equally, organizational outcomes are presented. Based on these findings, we indicated knowledge gaps and developed an agenda for further research to account for our second research question. Future research should assess the moderating role of internal and exogenous factors like dynamic capabilities, organizational structuring, or ecosystem dynamics. Especially the how, why, and when of organizational and process transformations to realize DBS is significant and should be assessed using different conceptual lenses and research approaches.
These findings highlight the contributions of this research: For practice, it focuses on the relevance of digital business strategies that will replace the demand for business-IT alignment and will become imperative for managers in the future. In view of the scientific community, the study suggests the need to question current assumptions on the strategizing process due to the digitalization and emergence of DBS. A structured description of the current knowledge base on DBS and related content elements as well as an agenda for future research are also introduced.

Nevertheless, the study faces some limitations with regard to the research approach: Publications may remain unaddressed due to the search terms focusing on digitalization in combination with strategies. Equally, the novelty of the topic might impact the publication state, so that more intense consideration of conference papers might have been of interest.

\section{References}

[1] Ambrosini, V. and Bowman, C. What are dynamic capabilities and are they a useful construct in strategic management? International journal of management reviews 11, 1 (2009), 29-49.

[2] Aubert, B.A., Kishore, R., and Iriyama, A. Exploring and managing the "innovation through outsourcing" paradox. Journal of Strategic Information Systems 24, 4 (2015), 255269.

[3] Banker, R.D., Hu, N., Pavlou, P.A., and Luftman, J. Cio Reporting Structure, Strategic Positioning, and Firm Performance. MIS Quarterly 35, 2 (2011), 487-504.

[4] Bashiri, I., Engels, C., and Heinzelmann, M. Strategic Alignment: Zur Ausrichtung von Business, IT und Business Intelligence. Springer-Verlag, 2010.

[5] Bass, F. A New Product Growth for Model Consumer Durables. Management Science 15, 5 (1969), 215-227.

[6] Bennis, W. Leadership in a Digital World: Embracing Transparency and Adaptive Capacity. MIS Quarterly 37, 2 (2013), 635-636.

[7] Berman, S. Digital Transformation: Opportunities to Create New Business Models. Strategy \& Leadership 40, 2 (2012), 16-24.

[8] Bharadwaj, A., El Sawy, O.A., Pavlou, P.A., and Venkatraman, N. Digital business strategy: Toward a next generation of insights. MIS Quarterly 37, 2 (2013), 471-482.

[9] Bharadwaj, A., El Sawy, O.A., Pavlou, P.A., and Venkatraman, N. Visions and Voices on Emerging Challenges in Digital Business Strategy. MIS Quarterly 37, 2 (2013), 633-634.

[10] Castrogiovanni, G.J. Environmental Munificence: A Theoretical Assessment. The Academy of Management Review 16, 3 (1991), 542-565.

[11] Chan, Y.E. and Reich, B.H. IT alignment: what have we learned? Journal of Information Technology 22, 4 (2007), 297-315. 
[12] Collin, J. Digitalization and Dualistic IT. In J. Collin, K. Hiekkanen, J. Korhonen, M. Halén, T. Itälä and M. Helenius, eds., IT Leadership in Transition: The Impact of Digitalization on Finnish Organizations. Aalto University School of Science, Helsinki, 2015, 29-34.

[13] Coltman, T., Tallon, P., Sharma, R., and Queiroz, M. Strategic IT alignment: twenty-five years on. Journal of Information Technology 30, 2 (2015), 91-100.

[14] Cooper, H.M. Synthesizing Research: A Guide for Literature Reviews. SAGE Publications, 1998.

[15] Dehning, B., Richardson, V.J., and Zmud, R.W. The Value Relevance of Announcements of Transformational Information Technology Investments. MIS Quarterly 27, 4 (2003), 637-656.

[16] Dehning, B. and Stratopoulos, T. Determinants of a sustainable competitive advantage due to an IT-enabled strategy. Journal of Strategic Information Systems 12, 1 (2003), 7-28.

[17] Dhar, V. and Sundararajan, A. Issues and OpinionsInformation Technologies in Business: A Blueprint for Education and Research. Information Systems Research 18, 2 (2007), 125-141.

[18] Drees, J.M. and Heugens, P.P. Synthesizing and extending resource dependence theory a meta-analysis. Journal of Management, (2013), 1666-1698.

[19] Drnevich, P.L. and Croson, D.C. Information Technology and Business-Level Strategy: Toward an Integrated Theoretical Perspective. MIS Quarterly 37, 2 (2013), 483-509.

[20] Eisenhardt, K.M. and Martin, J.A. Dynamic capabilities: what are they? Strategic management journal 21, 10-11 (2000), 1105-1121.

[21] El Sawy, O.A., Malhotra, A., YoungKi Park, and Pavlou, P.A. Seeking the Configurations of Digital Ecodynamics: It Takes Three to Tango. Information Systems Research 21, 4 (2010), 835-848.

[22] Elliot, S. Transdisciplinary perspectives on environmental sustainability: a resource base and framework for IT-enabled business transformation. MIS Quarterly 35, 1 (2011), 197-236.

[23] Fitzgerald, M., Kruschwitz, N., Bonnet, D., and Welch, M. Embracing Digital Technology: A New Strategic Imperative. Capgemini Consulting, 2013.

[24] Ganguly, A. Optimization of IT and Digital

Transformation: Strategic Imperative for Creating a New Value Delivery Mechanism and Sustainable Future in Organization. European Journal of Business and Innovation Research 3, 2 (2015), 1-13.

[25] Granados, N. and Gupta, A. Transparency Strategy:

Competing with Information in a Digital World. MIS Quarterly 37, 2 (2013), 637-641.

[26] Gregory, R.W., Keil, M., Muntermann, J., and Mähring, M. Paradoxes and the Nature of Ambidexterity in IT Transformation Programs. Information Systems Research 26, 1 (2015), 57-80.

[27] Hannan, M.T., Pólos, L., and Carroll, G.R. The evolution of inertia. Industrial and Corporate Change 13, 1 (2004), 213-242.
[28] Henderson, J.C. and Venkatraman, H. Strategic alignment: Leveraging information technology for transforming organizations. IBM Systems Journal 32, 1 (1993), 472-484.

[29] Hiekkanen, K. Strategic Alignment and Internal IT. In J. Collin, K. Hiekkanen, J. Korhonen, M. Halén, T. Itälä and M. Helenius, eds., IT Leadership in Transition: The Impact of Digitalization on Finnish Organizations. Aalto University School of Science, Helsinki, 2015, 44-49.

[30] Hitt, M.A., Tihanyi, L., Miller, T., and Connelly, B. International diversification: Antecedents, outcomes, and moderators. Journal of Management 32, 6 (2006), 831-867.

[31] Homburg, C., Hoyer, W.D., and Fassnacht, M. Service Orientation of a Retailer's Business Strategy: Dimensions, Antecedents, and Performance Outcomes. Journal of Marketing 66, 4 (2002), 86-101.

[32] ITWeb. Brainstorm CIO Survey. 2014.

[33] Jansen, J.J.P., Van Den Bosch, F.A.J., and Volberda, H.W. Exploratory Innovation, Exploitative Innovation, and Performance: Effects of Organizational Antecedents and Environmental Moderators. Management Science 52, 11 (2006), 1661-1674.

[34] Keen, P. and Williams, R. Value Architectures for Digital Business: Beyond the Business Model. MIS Quarterly 37, 2 (2013), 643-647.

[35] Korhonen, J. IT in Enterprise Transformation. In J. Collin, K. Hiekkanen, J. Korhonen, M. Halén, T. Itälä and M. Helenius, eds., IT Leadership in Transition: The Impact of Digitalization on Finnish Organizations. Aalto University School of Science, Helsinki, 2015, 35-43.

[36] Kraatz, M.S. and Zajac, E.J. How organizational resources affect strategic change and performance in turbulent environments: Theory and evidence. Organization Science 12, 5 (2001), 632-657.

[37] Lucas Jr., H.C., Agarwal, R., Clemons, E.K., El Sawy, O.A., and Weber, B. Impactful Research on Transformational Information Technology: An Opportunity to Inform New Audiences. MIS Quarterly 37, 2 (2013), 371-382.

[38] Luftman, J. and Brier, T. Achieving and Sustaining Business-IT Alignment. California Management Review 42, 1 (1999), 109-122.

[39] Lusch, R.F. and Nambisan, S. Service Innovation: A Service-Dominant Logic Perspective. MIS Quarterly 39, 1 (2015), 155-176.

[40] Lusch, R.F., Vargo, S.L., and O’Brien, M. Competing through service: Insights from service-dominant logic. Journal of Retailing 83, 1 (2007), 5-18.

[41] Maes, R., Rijsenbrij, D., Truijens, O., Goedvolk, H., and others. Redefining business: IT alignment through a unified framework. (2000).

[42] Mangan, J., Lalwani, C., and Gardner, B. Combining quantitative and qualitative methodologies in logistics research. International Journal of Physical Distribution and Logistics Management 34, (2004), 565-578.

[43] Mao, T., Kao, D., and Stomp, J. IS Strategy Formulation in the Digital Value Domain. Sustainability, Innovation and Global Supply Chain Management, Decision Sciences Institute (2012), 124-130. 
[44] Markus, M.L. and Loebbecke, C. Commoditized Digital Processes and Business Community Platforms: New Opportunities and Challenges for Digital Business Strategies. MIS Quarterly 37, 2 (2013), 649-653.

[45] Matt, C., Hess, T., and Benlian, A. Digital

Transformation Strategies. Business \& Information Systems Engineering 57, 5 (2015), 339-343.

[46] Mayring, P. Qualitative content analysis. Forum: Qualitative Social Research, (2000), 2-0.

[47] McKeown, I. and Philip, G. Business transformation, information technology and competitive strategies: learning to fly. International Journal of Information Management 23, 1 (2003), 3-24.

[48] Merali, Y., Papadopoulos, T., and Nadkarni, T. Information systems strategy: Past, present, future? Journal of Strategic Information Systems 21, 2 (2012), 125-153.

[49] Mithas, S., Agarwal, R., and Courtney, H. Digital Business Strategies and the Duality of IT. IT Professional 5, (2012), 2-4.

[50] Mithas, S. and Lucas Jr, H.C. What is Your Digital Business Strategy? IT Professional 12, 6 (2010), 4-6.

[51] Mithas, S., Ramasubbu, N., and Sambamurthy, V. How Information Management Capability Influences Firm Performance. MIS Quarterly 35, 1 (2011), 237-256.

[52] Mithas, S., Tafti, A., and Mitchell, W. How a Firm's Competitive Environment and Digital Strategic Posture Influence Digital Business Strategy. MIS Quarterly 37, 2 (2013), 511-536.

[53] Muzyka, D., De Koning, A., and Churchill, N. On transformation and adaptation: Building the entrepreneurial corporation. European Management Journal 13, 4 (1995), 346-362.

[54] Nienhüser, W. Resource dependence theory-How well does it explain behavior of organizations? management revue, (2008), 9-32.

[55] Pagani, M. Digital Business Strategy and Value Creation: Framing the Dynamic Cycle of Control Points. MIS Quarterly 37, 2 (2013), 617-632.

[56] Pavlou, P.A. and El Sawy, O.A. From IT Leveraging

Competence to Competitive Advantage in Turbulent Environments: The Case of New Product Development. Information Systems Research 17, 3 (2006), 198-227.

[57] Peppard, J., Galliers, R.D., and Thorogood, A.

Information systems strategy as practice: Micro strategy and strategizing for IS. The Journal of Strategic Information Systems 23, 1 (2014), 1-10.

[58] Peppard, J. and Ward, J. Beyond strategic information systems: towards an IS capability. The Journal of Strategic Information Systems 13, 2 (2004), 167-194.

[59] Pettigrew, A.M. Context and action in the transformation of the firm. Journal of management studies 24, 6 (1987), 649-670.

[60] Pfeffer, J. and Salancik, G.R. The external control of organizations: A resource dependence approach. NY: Harper and Row Publishers, (1978).

[61] PwC. Redefining business success in a changing world. 19th Annual Global CEO Survey. 2016.
[62] Raisch, S. and Birkinshaw, J. Organizational Ambidexterity: Antecedents, Outcomes, and Moderators. Journal of Management, (2008).

[63] Rajagopalan, N. and Spreitzer, G. Toward a Theory of Strategic Change: A Multi-lens Perspective and Integrative Framework. The Academy of Management Review 22, 1 (1997), 48-79.

[64] Rothmann, W. and Koch, J. Creativity in strategic lockins: The newspaper industry and the digital revolution.

Technological Forecasting and Social Change 83, (2014), 66-83.

[65] Sandberg, J. Digital Capability - Investigating Coevolution of IT and Business Strategies. 2014.

[66] Setia, P., Venkatesh, V., and Joglekar, S. Leveraging Digital Technologies: How Information Quality Leads to Localized Capabilities and Customer Service Performance. MIS Quarterly 37, 2 (2013), 565-A4.

[67] Sydow, J., Schreyögg, G., and Koch, J. Organizational path dependence: Opening the black box. Academy of Management Review 34, 4 (2009), 689-709.

[68] Teece, D.J., Pisano, G., and Shuen, A. Dynamic capabilities and strategic management. Strategic Management Journal 18, 7 (1997), 509-533.

[69] Urbach, N., Smolnik, S., and Riempp, G. The state of research on information systems success. Business \& Information Systems Engineering 1, 4 (2009), 315-325.

[70] Vukanovic, Z. Global paradigm shift: Strategic management of new and digital media in new and digital economics. The International Journal on Media Management 11, 2 (2009), 81-90.

[71] Webster, J. and Watson, R.T. Analyzing the past to prepare for the future: Writing a literature review. MIS Quarterly 26, 2 (2002), xiii-xxiii.

[72] Wenzel, M., Schmidt, T., and Fuerstenau, D. The Path Biography Methodology: Analyzing Self-Reinforcing Mechanisms on Technical and Organizational Levels. ICIS 2015 Proceedings, (2015).

[73] Wenzel, M., Wagner, D., Wagner, H.-T., and Koch, J. Digitization and path disruption: An examination in the funeral industry. ECIS 2015 Proceedings, (2015).

[74] Wolfswinkel, J.F., Furtmueller, E., and Wilderom, C.P.M. Using grounded theory as a method for rigorously reviewing literature. European Journal of Information Systems 22, 1 (2013), 45-55.

[75] Woodard, C.J., Ramasubbu, N., Tschang, F.T., and Sambamurthy, V. Design Capital and Design Moves: The Logic of Digital Business Strategy. MIS Quarterly 37, 2 (2013), 537-564.

[76] Yoo, Y., Henfridsson, O., and Lyytinen, K. Research Commentary - The New Organizing Logic of Digital Innovation: An Agenda for Information Systems Research. Information Systems Research 21, 4 (2010), 724-735.

[77] Zollo, M. and Winter, S.G. Deliberate learning and the evolution of dynamic capabilities. Organization science 13, 3 (2002), 339-351. 